\title{
Respiratory Infections in Infants: Interaction of Parental Allergy, Child Care, and Siblings-The PIAMA Study
}

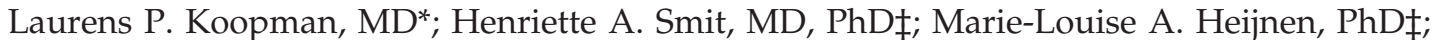 \\ Alet Wijga, PhD ; Rob T. van Strien, MSc§; Marjan Kerkhof, MD\|; Jorrit Gerritsen, MD, PhD\|; \\ Bert Brunekreef, PhD§; Johan C. de Jongste, MD, PhD*; and Herman J. Neijens, MD, PhD*
}

\begin{abstract}
Objective. To investigate the association between contacts with other children and the development of respiratory infections in the first year of life in children with or without genetic predisposition for allergy.

Methods. Children $(n=4146)$ who participate in a prospective birth cohort study (Prevention and Incidence of Asthma and Mite Allergy study) were investigated. Questionnaires were used to obtain information on doctor-diagnosed upper respiratory tract infection (URTI) and lower respiratory tract infection (LRTI), child care attendance, having siblings, family history of allergic disease, and various potential confounders.

Results. Child care attendance in the first year of life was associated with doctor-diagnosed URTI (adjusted odds ratio [AOR]: $2.7 ; 95 \%$ confidence interval [CI]: 2.13.4 for large child care facility vs no child care) and doctor-diagnosed LRTI (AOR: 5.6; 95\% CI: 3.9-7.9). Having siblings was associated with doctor-diagnosed LRTI (AOR: 2.6; 95\% CI: 2.0-3.4). In addition, children who have allergic parents and attend child care or have older siblings have a higher risk of developing doctor-diagnosed LRTI than do children who have nonallergic parents.

Conclusions. Child care attendance or having siblings increases the risk of developing doctor-diagnosed LRTI in the first year of life to a greater extent in allergy-prone children than in children who are not allergy prone. Pediatrics 2001;108:943-948; upper and lower respiratory tract infection, allergy, day care, and siblings.
\end{abstract}

ABBREVIATIONS. URTI, upper respiratory tract infection; LRTI, lower respiratory tract infection; AOR, adjusted odds ratio; $\mathrm{CI}$ confidence interval; PIAMA, Prevention and Incidence of Asthma and Mite Allergy.

From the *Department of Pediatrics, Sophia Children's Hospital, Erasmus

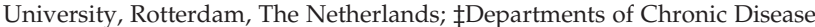
Epidemiology and Infectious Diseases Epidemiology, National Institute of Public Health and the Environment, Bilthoven, The Netherlands; §Department of Environmental and Occupational Health, Institute for Risk Assessment Sciences, University of Utrecht, Utrecht, The Netherlands; and ||Beatrix Children's Hospital, Groningen University, Groningen, The Netherlands.

Received for publication Nov 10, 2000; accepted Feb 13, 2001.

Reprint requests to (L.P.K.) Sophia Children's Hospital, Department of Pediatrics, Box 2060, 3000 CB, Rotterdam, The Netherlands. E-mail koopman@alkg.azr.nl

PEDIATRICS (ISSN 0031 4005). Copyright @ 2001 by the American Academy of Pediatrics.
$\mathrm{R}$ espiratory infections in infancy are common and account for considerable morbidity, doctor visits, hospital admissions, and health care costs. ${ }^{1,2}$ Various risk factors for upper respiratory tract infections (URTI) and lower respiratory tract infections (LRTI) in children have been identified, such as child care attendance, having older siblings, exposure to environmental tobacco smoke, young motherhood, low socioeconomic status, male gender, premature birth, low birth weight, born in the winter, and formula feeding. ${ }^{2-15}$ Although a parental history of allergic disease is thought to be associated with an increased risk of upper and lower respiratory symptoms, ${ }^{16,17}$ few studies have addressed this issue in relation to the URTI and LRTI in early life. ${ }^{3}$

The Prevention and Incidence of Asthma and Mite Allergy (PIAMA) Study is a combined effort of the University of Utrecht, the Sophia Children's Hospital Rotterdam, the Beatrix Children's Hospital of University Hospital Groningen, the Central Laboratory of the Red Cross Blood Transfusion Service, and the National Institute of Public Health and the Environment. This prospective, birth cohort study includes children from both allergic and nonallergic parents. The genetic background of our cohort gave us the opportunity to study whether the parental history of allergic disease interacts with and child care attendance having siblings in the development of respiratory tract infections.

\section{METHODS}

\section{Study Population}

Recruitment of the cohort took place during the first trimester of pregnancy and was conducted by 52 midwife practices in 3 different regions in the Netherlands: north (Groningen and surroundings), central (Bilthoven and Wageningen and surroundings), and southwest (Rotterdam and surroundings). In total, 7862 pregnant women were asked to participate in the study, and 4146 (53\%) agreed. The 4146 children have been followed from birth. In this cohort, 1327 have an allergic mother and are considered as high-risk children. The remaining 2819 children have a nonallergic mother and are considered low-risk children. The study includes an intervention part and a natural history part.

Some of the high-risk children (855) were allocated to the intervention part of the study. Half of those children received house dust mite impermeable mattress covers for the parental and infant bed (active group), and the other half received cotton mattress covers (placebo group). In the natural history part of the study (no intervention), 472 high-risk children (second control group to the intervention study) and 2819 low-risk children were included.

The participating children were born between May 1996 and December 1997. The definition of allergy in the mother was based 
on a validated screening questionnaire. ${ }^{18}$ Women with any of the following self-reported symptoms were defined as allergic, and their children were defined as high risk: asthma, hay fever, house dust allergy, house dust mite allergy, or pet allergy. Women who reported not having any of these symptoms were defined as nonallergic (and their children were defined as low risk). The PIAMA study was approved by the local medical ethical committees.

\section{Data Collection}

Questionnaires were sent to the participating parents during the third trimester of pregnancy, when the child was 3 months of age, and when the child was 1 year of age. Information was collected on birth characteristics (duration of pregnancy, gender, birth weight, length and head circumference, season of birth), indoor environmental factors (smoking by the parents, having pets, housing characteristics), socioeconomic characteristics (parental education and employment status), lifestyle factors (method of feeding, child care), and demographic factors (siblings, parental age).

\section{Outcome Variables}

When the children were 1 year of age, parents were asked whether their child had a doctor-diagnosed flu/serious cold, throat infection, middle-ear infection, bronchitis, pneumonia, pertussis, or any other serious respiratory tract infections. On the basis of the information mentioned above, 3 outcome groups were created:

1. Doctor-diagnosed URTI: children who had a doctor-diagnosed flu/serious cold, throat infection, or middle-ear infection but without doctor-diagnosed bronchitis, pneumonia, pertussis, or any other serious respiratory infection.

2. Doctor-diagnosed LRTI: children with doctor-diagnosed bronchitis or pneumonia irrespective of any doctor-diagnosed flu/ serious cold, throat infection, middle-ear infection, pertussis or any other serious respiratory infection.

3. Healthy control group: children without any report of doctordiagnosed flu/serious cold, throat infection, middle-ear infection, bronchitis, pneumonia, pertussis, or any other serious respiratory infection.

We anticipated that many children would develop both a doctor-diagnosed URTI and LRTI in the first year of life, which might interfere with the calculation of the associations between these 2 outcomes and various risk factors. For this reason, we defined doctor-diagnosed URTI as the development of a doctor-diagnosed flu/serious cold, otitis, or throat infection without any other respiratory infections. Ideally, doctor-diagnosed LRTI should have been defined as doctor-diagnosed bronchitis or pneumonia without any other respiratory disease. Because a large majority of children with a LRTI also experienced a URTI or other serious infections, we decided to include all of the children with reported doctor-diagnosed bronchitis or pneumonia in the group with doctor-diagnosed LRTI.

\section{Exposures of Interest}

Child care attendance was divided into 3 groups: 1) children who did not attend any form of child care in the first year of life and did not have regular contact with children other than their siblings (no child care), 2) children who were cared for regularly by relatives or foster parents and have contact with small numbers of children other than their siblings (small child care groups with $<5$ children), and 3 ) children who attend large child care facilities (large child care, groups usually $>10$ ). The allergic disease status of the father was assessed by using the same validated questionnaire as was used for the mother. The allergic status of the siblings was assessed by using the ISAAC questionnaire. ${ }^{19}$

\section{Statistical Analysis}

Crude odds ratios, adjusted odds ratios (AOR), and 95\% confidence intervals (CI) were estimated for the association between various risk factors and respiratory tract infections by using crosstabulation and logistic regression analysis (SPSS Version 8.0; SPSS, Inc, Chicago, IL). The healthy control group was used as the reference group in all analyses. The following 9 potential confounders were included in the model: type of study (intervention or natural history), maternal age, gender, season of birth, parental history of allergic disease, type of feeding, maternal smoking during pregnancy, maternal employment status, and level of education of the parents. On the basis of the parental history of allergic disease in combination with known risk factors for the development of respiratory infections (eg, child care attendance, having siblings), the infants were stratified into various subgroups. Interaction variables were constructed to test the joint impact of the parental history of allergic disease and exposure to other known risk factors on the development of respiratory infections. For instance, the 2 dummy variables of child care attendance were multiplied by the 3 dummy variables of parental history of allergic disease, resulting in an interaction term, which was entered into the logistic regression model.

\section{RESULTS}

\section{Response}

From the 4146 participants, 3745 (90\%) completed a questionnaire when the child was 1 year of age. From the remaining 401 families, 112 dropped out before the child was 1 year of age for various reasons (perinatal death, moved, language barrier, not interested); 289 parents did not complete a 1-year questionnaire but are still participating in the study. Another group of 327 parents completed a 1-year questionnaire, but data were incomplete for 1 or more confounders. A complete data set with the outcome variables and confounders was available for 3418 participants (82\%). Children with incomplete data were more likely (in comparison with children with complete data) to have an allergic mother $(44 \%$ vs $29 \%$ ), to have an asthmatic mother (12\% vs $7 \%$ ), to have a mother who smoked during the whole pregnancy (21\% vs 14\%), to be exposed to environmental tobacco smoke at 3 months (39\% vs $27 \%$ ), to live in an apartment (11\% vs $6 \%$ ), and to be bottle fed exclusively at 3 months of age (62\% vs 52\%). All other characteristics were similar in both groups. In this article, data used are from the 3418 children with complete data at 1 year of age.

\section{General Characteristics}

The general characteristics of the study population, stratified for allergic disease status of the parents, are shown in Table 1. Children from allergic parents were slightly more likely to have been breastfed at 3 months of age and less likely to have been exposed to maternal smoking during the whole pregnancy as compared with children from nonallergic parents.

\section{Incidence of Respiratory Infections}

The cumulative incidences of URTI and LRTI in the first year of life are summarized in Table 2. Medication was prescribed for $66 \%$ of the children with a flu/serious cold, for $77 \%$ of the children with a throat infection, and for $84 \%$ of the children with a middle-ear infection. Ninety-two percent of the children with bronchitis received medication, and hospitalization was needed for $4 \%$ of the children. All children with reported pneumonia received medication, and $43 \%$ were hospitalized. The majority of children $(78 \%)$ who experienced doctor-diagnosed LRTI also had a doctor-diagnosed URTI in the first year of life. 
TABLE 1. General Characteristics of the Study Population, Stratified for Parental History of Allergic Disease

\begin{tabular}{|c|c|c|c|c|c|}
\hline Characteristic & $\begin{array}{l}\text { Both Parents } \\
\text { Nonallergic } \\
(n=1700)\end{array}$ & $\begin{array}{l}\text { Mother } \\
\text { Allergic } \\
(n=677)\end{array}$ & $\begin{array}{l}\text { Father } \\
\text { Allergic } \\
(n=710)\end{array}$ & $\begin{array}{c}\text { Both Parents } \\
\text { Allergic } \\
(n=331)\end{array}$ & $\begin{array}{c}\text { Total } \\
(n=3418)\end{array}$ \\
\hline Male gender $(\%)$ & 50.8 & 52.7 & 52.3 & 47.4 & 51.1 \\
\hline $\begin{array}{l}\text { Maternal age (mean y } \pm \text { standard } \\
\text { deviation) }\end{array}$ & $30.4(3.9)$ & $30.1(3.7)$ & $30.5(3.8)$ & $30.0(4.1)$ & $30.3(3.9)$ \\
\hline \multicolumn{6}{|l|}{ Duration of pregnancy } \\
\hline $37-40 \mathrm{wk}(\%)$ & 44.4 & 43.0 & 47.7 & 48.5 & 45.2 \\
\hline$>40$ wk $(\%)$ & 51.0 & 52.2 & 48.4 & 45.7 & 50.2 \\
\hline$<37$ wk $(\%)$ & 4.6 & 4.8 & 3.8 & 5.9 & 4.6 \\
\hline $\begin{array}{l}\text { Birth weight (mean } g \pm \text { standard } \\
\text { deviation) }\end{array}$ & $3512(539)$ & $3502(570)$ & $3527(518)$ & $3452(398)$ & $3507(547)$ \\
\hline \multicolumn{6}{|l|}{ Season of birth } \\
\hline Winter & 17.1 & 20.8 & 19.4 & 19.0 & 18.5 \\
\hline Spring & 25.1 & 24.4 & 22.5 & 20.8 & 24.0 \\
\hline Summer & 31.4 & 23.6 & 31.1 & 27.8 & 29.5 \\
\hline Fall & 26.4 & 31.2 & 26.9 & 32.3 & 28.0 \\
\hline \multicolumn{6}{|l|}{ Method of feeding } \\
\hline Only breastfeeding at 3 mo of age & 30.2 & 31.6 & 32.7 & 36.0 & 31.5 \\
\hline Breastfeeding and formula at $3 \mathrm{mo}$ & 16.8 & 17.4 & 17.2 & 15.4 & 16.9 \\
\hline Only formula feeding at $3 \mathrm{mo}$ & 53.0 & 51.0 & 50.1 & 48.6 & 51.6 \\
\hline$\%$ with at least 1 older sibling & 52.1 & 48.2 & 51.7 & 47.4 & 50.8 \\
\hline Siblings with allergic disease ( $\%$ of total)* & 22.3 & 30.2 & 28.7 & 30.6 & 26.0 \\
\hline \multicolumn{6}{|l|}{ Form of child caret } \\
\hline No child care $(\%)$ & 35.1 & 36.3 & 31.8 & 34.4 & 34.6 \\
\hline Child care small group (\%) & 41.8 & 40.8 & 41.0 & 41.4 & 41.4 \\
\hline Child care large group $(\%)$ & 23.1 & 22.9 & 27.2 & 24.2 & 24.0 \\
\hline \multicolumn{6}{|l|}{ Smoking mother during pregnancy } \\
\hline No smoking (\%) & 79.6 & 83.3 & 82.8 & 83.4 & 81.4 \\
\hline Only first trimester $(\%)$ & 4.4 & 3.8 & 4.5 & 4.8 & 4.3 \\
\hline Whole pregnancy $(\%)$ & 16.0 & 12.9 & 12.7 & 11.8 & 14.3 \\
\hline Both parents low level of education $\ddagger(\%)$ & 6.5 & 6.6 & 5.6 & 6.9 & 6.4 \\
\hline
\end{tabular}

* Allergic disease in siblings defined as having a history of asthma, eczema, hay fever, or other inhalant allergies.

† No child care $=$ no form of child care at all; small child care $=$ regularly cared for by relatives or foster parents and contact with small numbers of children other than their siblings; large child care = child care centers, usually 10 or more children.

$\ddagger$ Both parents have a maximum of 4 years high school education.

TABLE 2. Cumulative 12-Month Incidence (\%) of URTI and LRTI Stratified for Parental History of Allergic Disease

\begin{tabular}{|c|c|c|c|c|c|}
\hline Type of Respiratory Tract Infection & $\begin{array}{l}\text { Both Parents } \\
\text { Nonallergic } \\
(n=1700)\end{array}$ & $\begin{array}{l}\text { Mother } \\
\text { Allergic } \\
(n=677)\end{array}$ & $\begin{array}{c}\text { Father } \\
\text { Allergic } \\
(n=710)\end{array}$ & $\begin{array}{c}\text { Both Parents } \\
\text { Allergic } \\
(n=331)\end{array}$ & $\begin{array}{c}\text { Total } \\
(n=3418)\end{array}$ \\
\hline Doctor-diagnosed flu/serious cold & 42.2 & 48.7 & 45.8 & 53.5 & 45.3 \\
\hline Doctor-diagnosed throat infection & 5.8 & 7.4 & 8.2 & 9.1 & 6.9 \\
\hline Doctor-diagnosed middle-ear infection & 17.2 & 16.8 & 18.3 & 19.6 & 17.6 \\
\hline Doctor-diagnosed bronchitis & 13.8 & 15.1 & 15.6 & 16.9 & 14.7 \\
\hline Doctor-diagnosed pneumonia & 2.1 & 2.5 & 3.2 & 2.7 & 2.5 \\
\hline 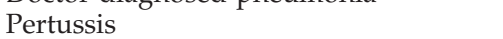 & 0.9 & 1.5 & 1.4 & 1.2 & 1.2 \\
\hline Other respiratory tract infections* & 11.7 & 15.7 & 13.4 & 13.1 & 13.0 \\
\hline Doctor-diagnosed URTI† & 31.8 & 33.7 & 30.0 & 34.4 & 32.1 \\
\hline Doctor-diagnosed LRTI & 15.0 & 15.8 & 17.6 & 19.0 & 16.1 \\
\hline
\end{tabular}

* Parents also were asked, "Did your child have any other respiratory tract infections than flu/serious cold, throat infection, middle ear infection, bronchitis, or pneumonia?"

+ Cumulative 12-month incidence of doctor-diagnosed URTI: flue/serious cold, throat infection, or middle-ear infection. Children with bronchitis, pneumonia, pertussis, or other respiratory infections were excluded.

$\ddagger$ Cumulative 12-month incidence of doctor-diagnosed LRTI: bronchitis or pneumonia irrespective of other respiratory disease.

\section{Risk Factors for Doctor-Diagnosed URTI and LRTI}

AOR for the association between contacts with other children, parental history of allergic disease, and URTI and LRTI are shown in Table 3. Child care attendance increased the risk for doctor-diagnosed LRTI and, to a lesser extent, for doctor-diagnosed URTI. Furthermore, the size of the child care group was positively related directly to the incidence of respiratory tract infections. Having 1 or more siblings (all siblings are older than the study subject) was a strong risk factor for doctor-diagnosed LRTI and was only weakly related to doctor-diagnosed URTI. Having an allergic father and having 2 allergic parents was weakly associated with the development of doctor-diagnosed LRTI but was not associated with doctor-diagnosed URTI.

In a multivariate analysis, maternal age, season of birth, type of feeding, and low level of education were associated with doctor-diagnosed URTI. Male gender, maternal age, and type of feeding all were risk factors for doctor-diagnosed LRTI (Table 3).

\section{Relation Between Contacts With Other Children and Respiratory Tract Infections}

Figures 1 and 2 show the AOR for the association between contact with other children (child care at- 
TABLE 3. Contacts With Other Children and Parental History of Allergic Disease and Other Factors in Relation to Respiratory Tract Infections in the First 12 Months of Life

\begin{tabular}{|c|c|c|c|c|}
\hline & \multicolumn{2}{|c|}{ URTI } & \multicolumn{2}{|c|}{ LRTI } \\
\hline & $\mathrm{AOR}^{*}$ & $95 \%$ CI & $\mathrm{AOR}^{*}$ & $95 \% \mathrm{CI}$ \\
\hline No child care & 1 & & 1 & \\
\hline Child care, small group & 1.4 & $1.2-1.7$ & 2.0 & $1.5-2.6$ \\
\hline Child care, large group & 2.7 & $2.1-3.4$ & 4.8 & $3.5-6.9$ \\
\hline Siblings & 1.2 & $1.0-1.5$ & 2.5 & $1.9-3.1$ \\
\hline No parent allergic & 1 & & 1 & \\
\hline Only mother allergic & 1.1 & $0.8-1.5$ & 1.2 & $0.8-1.8$ \\
\hline Only father allergic & 1.0 & $0.8-1.2$ & 1.2 & $0.9-1.6$ \\
\hline Both parents allergic & 1.2 & $0.8-1.7$ & 1.6 & $1.0-2.5$ \\
\hline \multicolumn{5}{|l|}{ Maternal smoking during pregnancy } \\
\hline No smoking & 1 & & 1 & \\
\hline Only smoking first trimester & 1.3 & $0.9-1.9$ & 1.5 & $0.9-2.8$ \\
\hline Smoking whole pregnancy & 1.0 & $0.7-1.2$ & 1.3 & $0.9-1.7$ \\
\hline Male gender & 1.0 & $0.8-1.1$ & 1.4 & $1.1-1.7$ \\
\hline $\begin{array}{l}\text { Maternal age (for each additional } \\
\text { year) }\end{array}$ & 0.97 & $0.95-1.00$ & 0.93 & $0.90-0.96$ \\
\hline \multicolumn{5}{|l|}{ Season of birth } \\
\hline Winter & 1 & & 1 & \\
\hline Spring & 0.9 & $0.7-1.2$ & 0.9 & $0.7-1.3$ \\
\hline Summer & 0.9 & $0.7-1.2$ & 0.9 & $0.7-1.3$ \\
\hline Fall & 0.8 & $0.6-1.0$ & 0.8 & $0.6-1.2$ \\
\hline \multicolumn{5}{|l|}{ Type of feeding at 3 mot } \\
\hline Exclusive breastfeeding & 1 & & 1 & \\
\hline Breastfeeding and formula & 1.4 & $1.1-1.8$ & 1.0 & $0.7-1.5$ \\
\hline Exclusive formula & 1.6 & $1.3-1.9$ & 1.5 & $1.1-1.9$ \\
\hline Low level of parental education & 1.4 & $1.0-2.0$ & 0.8 & $0.5-1.3$ \\
\hline
\end{tabular}

* Adjusted for type of study, employment of the mother, and the other risk factors, eg, results for siblings are adjusted for child care attendance, parental history of allergic disease, maternal smoking during pregnancy, gender, maternal age, season of birth, type of feeding, level of parental education. t OR adjusted like above* and also adjusted for birth weight and duration of pregnancy.

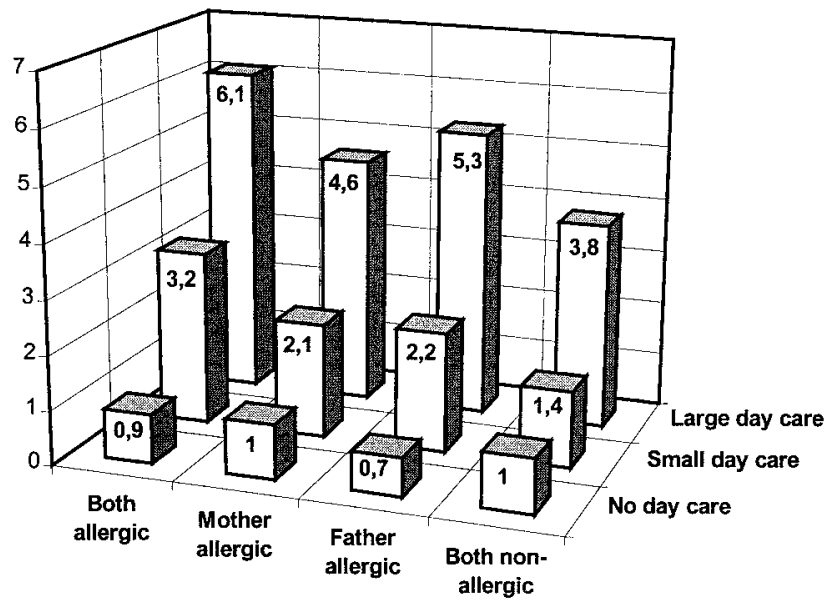

Fig 1. AOR for doctor-diagnosed LRTI in relation to type of child care, stratified for parental history of allergic disease.

tendance and having siblings) and doctor-diagnosed LRTI, stratified for parental history of allergic disease. The OR for doctor-diagnosed LRTI gradually increase when the children attend small or large child care centers (Fig 1). When the child does not attend any form of child care, parental allergy does not influence the risk for doctor-diagnosed LRTI; but when the child attends small or large child care facilities, the risk of developing an LRTI is markedly influenced by the parental allergic status. For instance, a child who attends small child care and has 2 allergic parents has a 3.2-fold increased risk of developing an LRTI as compared with the reference group (no child care, no allergic parents), whereas a

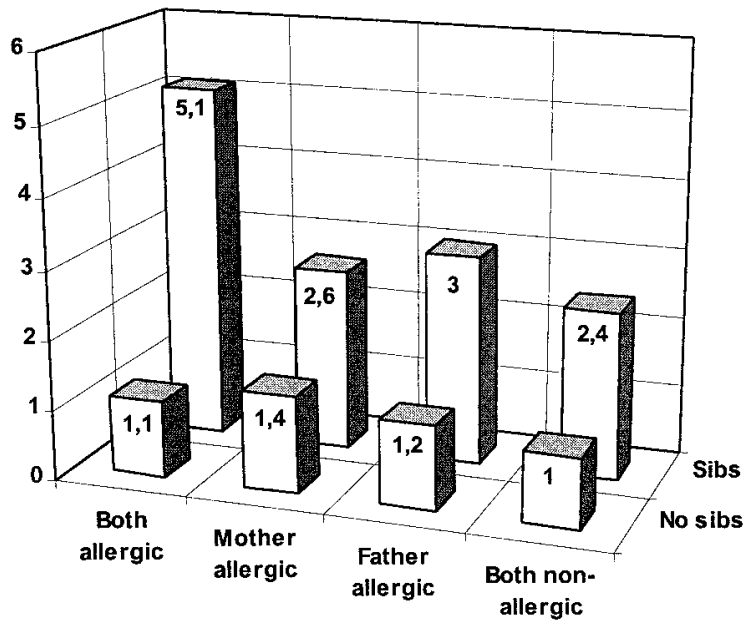

Fig 2. AOR for doctor-diagnosed LRTI in relation to having siblings, stratified for parental history of allergic disease.

child who attends small child care and has no allergic parents only has a 1.4-fold increased risk of developing an LRTI as compared with the reference group. A similar pattern is seen for increasing number of allergic parents and having siblings in relation to doctor-diagnosed LRTI (Fig 2). When interaction variables were entered in the logistic regression model for doctor-diagnosed LRTI, statistically significant interaction was found for "father allergic $x$ small child care" $(P=.02)$ and "father allergic $X$ large child care" $(P=.04)$ and "both parents allergic $\times$ small child care" $(P=.05)$. The interaction term "both parents allergic $\times$ having siblings" was bor- 
derline statistically significant $(P=.06)$. When the interaction variables were entered in the logistic regression model for doctor-diagnosed URTI, no significant associations were found (data not shown).

\section{DISCUSSION}

In this prospective birth cohort study, we found that in allergy-prone children, child care attendance and having siblings increase the risk of developing a doctor-diagnosed LRTI in infancy as compared with children without predisposition for allergy. This increased risk is higher than can be explained by the independent effect of the individual risk factors, which is suggestive for interaction.

\section{Validation Issues}

The parental reporting of respiratory tract infections could be related to child care, having siblings, or the allergic status of the parents, resulting in reporting bias. In our study, parents also reported on cough, runny nose, earache, fever, and doctor visits for these symptoms in the month before completing the 12-month questionnaire. We found that for these respiratory symptoms in the month before completion of the questionnaire, type of child care, having siblings, and allergic status of the parents were not related to doctor visits for these symptoms (data not shown). Therefore, it is unlikely that our results can be explained by reporting bias, although we have no data on potential reporting bias for lower respiratory symptoms. Symptoms of asthma or asthma-like disease could have been labeled inappropriately as LRTI, because in this age group, a distinction between these diseases is impossible. However, for reporting bias to explain the interaction that we found, it would have to operate selectively in allergic parents whose child goes to child care and/or has an older sibling, as in children without older siblings or child care, parental allergy had little influence on LRTI reporting. This seems unlikely.

\section{Cumulative Incidence of Respiratory Tract Infections}

We found a similar cumulative incidence of doctor-diagnosed LRTI as in a Norwegian Study that used the same criteria to define LRTI ${ }^{14}$ but a lower incidence as described in studies that used the term "lower respiratory illness." 1,7 The latter definition also includes various forms of wheezing illness and probably reflects a less severe outcome. ${ }^{4}$ The cumulative 1-year incidence of otitis media in our study $(18 \%)$ is comparable with some studies ${ }^{20,21}$ but low compared with other studies that found a cumulative incidence of more than $60 \% .9,15$ In the latter studies, the diagnosis was made by regular inspection of the tympanum, probably incorporating asymptomatic otitis media in the definition and therefore reflecting a less severe outcome.

\section{Child Care Attendance, Having Siblings, and Parental History of Allergic Disease in Relation to Respiratory Tract Infections}

There is little doubt that child care attendance is associated with an increased incidence of URTI and LRTI $^{3-5,9,22-24}$ and probably reflects an increased ex- posure to microorganisms. For instance, Celedon et $\mathrm{al}^{3}$ reported in a high-risk population (at least 1 parent was allergic) an OR of 1.6 (95\% CI: 1.0-2.4) for LRTI at age 1 in children who attended some form of child care. In the same study, child care in large groups was associated with a much higher risk of developing a LRTI as compared with child care in small groups. In a study by Marbury et al, ${ }^{4}$ child care attendance was associated with the development of lower respiratory tract illness in the first year of life (OR: 2.0; 95\% CI: 1.7-2.3). Also in their study, the risk of developing a lower respiratory tract illness increased with increasing group size. Our finding that having older siblings is related to doctor-diagnosed LRTI is in agreement with various other studies. ${ }^{3,6,13}$ Few data are available about the relationship between parental history of allergic disease and respiratory infections in their children. Our finding that having 2 allergic parents was associated with an increased risk of developing doctor-diagnosed LRTI (Table 3) is in agreement with the findings of 2 other studies. Leeder et $\mathrm{al}^{6}$ reported a higher incidence of bronchitis and pneumonia in children from asthmatic or wheezing parents than in children from symptom-free parents. Ponsonby et $\mathrm{al}^{13}$ found that having a family member with asthma was an independent predictor of developing a LRTI in the first year of life.

\section{Interaction Between Parental History of Allergic Disease and Contacts With Other Children}

To our knowledge, this is the first publication in which interaction between the parental history of allergic disease and contacts with other children (child care attendance and having siblings) for the development of respiratory infections in infancy is reported. Our results suggest that the combination of having allergic parents and high exposure to microorganisms increases the risk of developing a doctordiagnosed LRTI to a greater extent than can be expected from the independent effect of the individual risk factors. A possible explanation is that children from allergic parents have airways that are, for an unknown reason, more vulnerable to infections than airways of children from nonallergic parents. If children are not exposed to a high load of microorganisms (eg, in the case of a single child, when the child is cared for at home), then this increased vulnerability may not lead to serious infections. In contrast, if the infection load is higher (having siblings or, to a higher extent, attending child care), then the increased vulnerability as a result of genetic predisposition leads to an excessive increase in doctor-diagnosed LRTI. It is interesting that the interaction effect was greatest for children with an allergic father compared with children with an allergic mother or children with 2 allergic parents.

What are the implications of our findings for the prevention of LRTI in infancy? Obviously, decreasing contacts with siblings is mostly not desirable, but high exposure to microorganisms in child care facilities potentially can be avoided. It remains to be seen whether avoiding contact with other children in early life is beneficial in the long run. Two recent 
studies found an inverse relationship between child care attendance or having siblings in early life and the development of asthma and allergy in later childhood. ${ }^{25,26}$ The authors speculated that infections in early life stimulate the infant's immune response to shift from a predominantly type 2 helper T-cell(which is associated with the allergic phenotype) toward a type 1 helper T-cell-dominated response. So if in allergy-prone children child care attendance or having siblings increased the risk of LRTI (as was documented in the PIAMA study) and child care and having siblings in early life protect against asthma and allergy in later childhood, ${ }^{25}$ then an interesting question will be, "Do children from allergic parents benefit more from child care attendance and having older siblings than children from nonallergic parents, with respect to the later development of asthma?" Follow-up of our cohort might give more insight on this topic.

\section{CONCLUSION}

We found that child care attendance and having siblings increases the risk of developing doctor-diagnosed LRTI in the first year of life to a greater extent in allergy-prone children than in children who are not allergy prone. The relevance of this finding for future risk of allergic disease requires long-term follow-up.

\section{ACKNOWLEDGMENTS}

The PIAMA study is supported by the Netherlands Asthma Fund, the Ministry of the Environment, ZorgOnderzoek Nederland, and the National Institute of Public Health and the Environment.

\section{REFERENCES}

1. Wright AL, Taussig LM, Ray CG, Harrison HR, Holberg CJ. The Tucson Children's Respiratory Study. II. Lower respiratory tract illness in the first year of life. Am J Epidemiol. 1989;129:1232-1246

2. Ey JL, Holberg CJ, Aldous MB, Wright AL, Martinez FD, Taussig LM. Passive smoke exposure and otitis media in the first year of life. Group Health Medical Associates. Pediatrics. 1995;95:670-677

3. Celedon JC, Litonjua AA, Weiss ST, Gold DR. Day care attendance in the first year of life and illnesses of the upper and lower respiratory tract in children with a familial history of atopy. Pediatrics. 1999;104:495-500

4. Marbury MC, Maldonado G, Waller L. Lower respiratory illness, recurrent wheezing, and day care attendance. Am J Respir Crit Care Med. 1997; 155:156-161

5. Holberg CJ, Wright AL, Martinez FD, Morgan WJ, Taussig LM. Child day care, smoking by caregivers, and lower respiratory tract illness in the first 3 years of life. Group Health Medical Associates. Pediatrics. 1993:91:885-892

6. Leeder SR, Corkhill R, Irwig LM, Holland WW, Colley JR. Influence of family factors on the incidence of lower respiratory illness during the first year of life. Br I Prev Soc Med. 1976;30:203-212

7. Fergusson DM, Horwood LJ, Shannon FT, Taylor B. Parental smoking and lower respiratory illness in the first three years of life. J Epidemiol Community Health. 1981;35:180-184

8. Martinez FD, Wright AL, Holberg CJ, Morgan WJ, Taussig LM. Maternal age as a risk factor for wheezing lower respiratory illnesses in the first year of life. Am J Epidemiol. 1992;136:1258-1268

9. Paradise JL, Rockette HE, Colborn DK, et al. Otitis media in 2253 Pittsburgh-area infants: prevalence and risk factors during the first two years of life. Pediatrics. 1997;99:318-333

10. Margolis PA, Greenberg RA, Keyes LL, et al. Lower respiratory illness in infants and low socioeconomic status. Am J Public Health. 1992;82: 1119-1126

11. Greenough A, Giffin FJ, Yuksel B. Respiratory morbidity in preschool children born prematurely. Relationship to adverse neonatal events. Acta Paediatr. 1996;85:772-777

12. Rylander E, Eriksson M, Pershagen G, Nordvall L, Ehrnst A, Ziegler T. Wheezing bronchitis in children. Incidence, viral infections, and other risk factors in a defined population. Pediatr Allergy Immunol. 1996;7:6-11

13. Ponsonby AL, Couper D, Dwyer T, Carmichael A, Kemp A. Relationship between early life respiratory illness, family size over time, and the development of asthma and hay fever: a seven year follow up study. Thorax. 1999;54:664-669

14. Nafstad P, Jaakkola JJ, Hagen JA, Botten G, Kongerud J. Breastfeeding, maternal smoking and lower respiratory tract infections. Eur Respir J. 1996;9:2623-2629

15. Duncan B, Ey J, Holberg CJ, Wright AL, Martinez FD, Taussig LM. Exclusive breast-feeding for at least 4 months protects against otitis media. Pediatrics. 1993;91:867-872

16. Bergmann RL, Bergmann KE, Lau-Schadensdorf S, et al. Atopic diseases in infancy. The German multicenter atopy study (MAS-90). Pediatr Allergy Immunol. 1994;5:19-25

17. Camilli AE, Holberg CJ, Wright AL, Taussig LM. Parental childhood respiratory illness and respiratory illness in their infants. Group Health Medical Associates. Pediatr Pulmonol. 1993;16:275-280

18. Lakwijk N, Van Strien RT, Doekes G, Brunekreef B, Gerritsen J. Validation of a screening questionnaire for atopy with serum IgE tests in a population of pregnant Dutch women. Clin Exp Allergy. 1998;28: $454-458$

19. Asher MI, Keil U, Anderson HR, et al. International Study of Asthma and Allergies in Childhood (ISAAC): rationale and methods. Eur Respir J. 1995;8:483-491

20. Benediktsdottir B. Upper airway infections in preschool childrenfrequency and risk factors. Scand J Prim Health Care. 1993;11:197-201

21. Aniansson G, Alm B, Andersson B, et al. A prospective cohort study on breast-feeding and otitis media in Swedish infants. Pediatr Infect Dis J. 1994;13:183-188

22. Louhiala PJ, Jaakkola N, Ruotsalainen R, Jaakkola JJ. Form of day care and respiratory infections among Finnish children. Am J Public Health. 1995;85:1109-1112

23. Alho OP, Laara E, Oja H. Public health impact of various risk factors for acute otitis media in northern Finland. Am J Epidemiol. 1996;143: 1149-1156

24. Uhari M, Mantysaari K, Niemela M. A meta-analytic review of the risk factors for acute otitis media. Clin Infect Dis. 1996;22:1079-1083

25. Ball TM, Castro-Rodriguez JA, Griffith KA, Holberg CJ, Martinez FD, Wright AL. Siblings, day-care attendance, and the risk of asthma and wheezing during childhood. N Engl J Med. 2000;343:538-543

26. Kramer U, Heinrich J, Wjst M, Wichmann HE. Age of entry to day nursery and allergy in later childhood. Lancet. 1999;353:450-454 